\title{
Safe management of the UK separated plutonium inventory: a challenge of materials degradation
}

\author{
Neil C. Hyatt $\mathbb{D}^{1 凶}$
}

The UK holds the largest inventory, worldwide, of separated plutonium under civil safeguards. Here, the importance of materials degradation in managing this inventory to a safe and secure end point is reviewed, together with recent developments, in the context of storage, reuse and immobilisation and disposal.

npj Materials Degradation (2020)4:28; https://doi.org/10.1038/s41529-020-00132-7

After more than 50 years of successful operations, reprocessing of spent nuclear fuel will shortly come to an end on the Sellafield site $^{1}$. In so doing, the focus of the Sellafield site mission will shift exclusively to decommissioning of its nuclear facilities. Reprocessing of spent nuclear fuels has afforded a UK inventory of plutonium forecast to be 140 tons at the end of reprocessing operations (of which 23 tons are foreign-owned) ${ }^{2}$, Fig. 1. As discussed here, the continued safe and secure management of the UK plutonium inventory is underpinned by the need to understand the isotopic, chemical and physical degradation of this material, and its impact on the integrity of storage, potential for reuse, and immobilisation for disposal.

The original driver for the UK's inventory of civil separated plutonium was to fuel a fleet of commercial fast reactors ${ }^{2}$. However, although the fast reactor development programme was closed in 1994, reprocessing of nuclear fuel continued, affording the current inventory. In contrast to the spent fuel arising from the UK's advanced gas-cooled reactors, spent fuel from Magnox stations was designed to be reprocessed and was not intended to be directly disposed in significant quantity, due to its reactivity (magnesium alloy clad uranium metal) ${ }^{2}$. Consequently, Magnox derived plutonium constitutes the dominant fraction of the material within the UK plutonium inventory ${ }^{2}$.

The current UK government policy for management of its plutonium inventory was set out in $2011^{3,4}$, and specifies an intention for reuse of this material in MOX fuel (a Mixed OXide of uranium and plutonium):

The UK Government has concluded that for nuclear security reasons the preferred policy for managing the vast majority of UK civil separated plutonium is reuse and it, therefore, should be converted to MOX fuel for use in civil nuclear reactors. Any remaining plutonium whose condition is such that it cannot be converted into MOX will be immobilised and treated as waste for disposal.

This policy was informed by consideration of the credible options for plutonium management, published by the Nuclear Decommissioning Authority, in $2010^{5}$.

In the international context, there exist considerable declared stockpiles of separated plutonium in France, Russia, the United States of America, China, and Japan, see Fig. 2 and Box 1. Reuse of plutonium as MOX fuel in commercial light water reactors (LWRs) has been achieved in France and Japan, whereas, in contrast, the US MOX Fuel Fabrication Plant was terminated prior to completion of construction, as discussed below ${ }^{2}$. Reuse of civil plutonium as MOX or other fuel in sodium cooled fast breeder reactors has proven more challenging, although Russia and China have ambitious plans for multi-recycling of plutonium in such reactors.

\section{REUSE IN LIGHT WATER REACTORS}

In principle, the UK plutonium inventory could be sufficient to fuel three $1100 \mathrm{MWe}$ PWR (Pressurised Water Reactor) or $1600 \mathrm{MWe}$ EPR (European Pressurised water Reactor) units, over a 60 year life time, depending on the core loading. The challenge for the implementation of this policy is both economic and technical. At least 40 reactors have operated with a partial MOX core in Europe and MOX fuel manufacture has been developed at commercial scale by several vendors, most notably Orano (previously Areva), which has produced in excess of 2500 tons; geological disposal of spent MOX fuels is planned within several European programmes ${ }^{2}$. On the other hand, the UK's own experience with MOX fuel manufacture did not achieve the design throughput, and construction of the US MOX Fuel Fabrication Facility was terminated for technical, commercial and financial reasons ${ }^{2}$.

To increase confidence in reuse of plutonium in MOX fuels, research is underway to demonstrate the manufacture of MOX fuel pellets from UK plutonium, which has unique powder characteristics, isotopic composition, and significant americium241 ingrowth, from decay of plutonium-241 during storage. It is expected that the blending of plutonium batches will enable the americium-241 ingrowth to be adequately managed with respect to MOX fuel manufacture and utilisation ${ }^{1,2}$. Detailed neutronics studies have provided confidence that MOX fuels fabricated from this feedstock will perform acceptably in LWRs ${ }^{6,7}$. However, the manufacture of MOX fuels from UK plutonium remains to be demonstrated convincingly at the required commercial scale. Moreover, no UK reactor operator has yet signalled interest in MOX offtake, and uranium supply is expected to be sufficient to meet projected demand for the foreseeable future ${ }^{1,8}$. Collectively, these factors result in an undeniably weak economic driver for plutonium reuse as MOX fuel in LWRs, although it is a technically plausible solution. Other reuse options, such as in the CANDU EC6 reactor or GE PRISM fast reactors, were determined to present greater technical and implementation risks than reuse in LWRs; nevertheless, the CANDU EC6 system is considered to be a credible option ${ }^{1}$.

\footnotetext{
${ }^{1}$ Department of Materials Science \& Engineering, The University of Sheffield, Mappin Street, Sheffield S1 3JD, UK. ${ }^{\circledR}$ email: n.c.hyatt@sheffield.ac.uk
} 
Box 1: The international perspective

Internationally, more than 340 metric tons of separated plutonium were declared as holdings, by the nine countries reporting to the International Atomic Energy Agency (IAEA) under the Guidelines for the Management of Plutonium (INFCIRC/ 549), see Fig. 2. The status of plutonium management and spent fuel reprocessing for those nations with significant declared inventories of separated plutonium is summarised below.

France. Plutonium is separated at the La Hague reprocessing facility and fabricated into MOX fuel at the MELOX plant, Marcoule, for reuse in the PWR fleet. The long term strategy was for multi-recycling of plutonium, in a closed fuel cycle, using sodium cooled fast breeder reactor technology. Recycling of spent MOX fuel has been successfully demonstrated at the La Hague facility, however, development of the prototype $600 \mathrm{MWe}$ Advanced Sodium Technological Reactor for Industrial Demonstration (ASTRID) was cancelled in 2019

United States of America. The declared inventory of plutonium was designated as no longer required for defence purposes in 1997. Under the Plutonium Management and Disposition Agreement (PMDA) with Russia, it was planned that part of the inventory would be dispositioned as MOX fuel in LWRs, whereas part would be immobilised for disposal (in a tailored ceramic surrounded by vitrified high level waste). The USA later decided to implement only the MOX disposition option and committed to the construction of a MOX Fuel Fabrication Facility (MFFF) at the Savannah River site. Ultimately, the MFFF was terminated during construction after considerable time and cost over-runs; in response, Russia suspended implementation of the PMDA. It is now planned to mix the separated plutonium with a proprietary adulterant and dispose in the Waste Isolation Pilot Plant repository in New Mexico.

Russia. Plutonium is separated at the RT-1 reprocessing plant, located at Mayak, and the Pilot Demonstration Centre for spent fuel reprocessing facility, located at Mining and Chemical Combine (MCC) in Zheleznogorsk, is under commissioning. A MOX fuel fabrication facility is operational at the MCC Zheleznogorsk and has produced fuel assemblies for the BN-800, and future BN-1200, sodium cooled fast reactors. Under the PMDA, 34 tons of plutonium excess to defence needs was to be converted to MOX fuel in the Zheleznogorsk fuel fabrication facility for disposition in the BN-800 reactor; implementation of the PMDA was suspended by Russia in 2016 .

China. Plutonium is separated at the Jiuquan pilot reprocessing facility, with the intention of interim reuse in LWRs, and, in the long term, fuelling a fleet of sodium cooled fast reactors. A pilot MOX fuel fabrication plant has been constructed at Jiuquan to supply fuel for the $25 \mathrm{MWe}$ China Experimental Fast Reactor which has operated intermittently since 2010 (though it has yet to utilise MOX fuel). Construction of a demonstration scale reprocessing facility and MOX fuel fabrication plant are underway, to supply fuel to twin indigenous $600 \mathrm{MWe}$ demonstration fast reactors. Finally, China has plans for procurement of a commercial scale reprocessing facility (from France).

Japan. The Tokai Reprocessing Plant produced a mixture of uranium and plutonium oxides from recycle of $\mathrm{UO}_{2}$ and $\mathrm{MOX}$ fuel; this process will also be applied at the Rokkasho Nuclear Fuel Reprocessing Facility. In response to the Great East Japan earthquake, tsunami, and Fukushima Daiici accident in 2011, the Tokai facility was closed and the Rokkasho reprocessing and J-MOX fuel fabrication facilities were subject to additional safety measures which delayed commissioning. The J-MOX fuel fabrication facility will supply MOX fuel for LWRs, which have already utilised MOX fuel produced in France under commercial reprocessing contracts. The future strategy is for plutonium reuse in fast reactors, however, the 280 MWe Monju prototype fast reactor was closed in 2016.

The current credible options for management of the UK plutonium inventory are summarised in the following paragraphs, with a focus on the important role of materials degradation in enabling progression to a safe and secure final end point.

\section{OPTIONS FOR IMMOBILISATION}

In supporting the UK government in progressing a final decision on plutonium disposition, the Nuclear Decommissioning Authority has commissioned a substantial research programme to determine the quantity of plutonium unsuitable for reuse in MOX fuel and to develop the technology for immobilisation ${ }^{1}$. Given the diversity and characteristics of UK plutonium, which span contaminated residues to fuel quality material, at least three approaches to immobilisation and disposal are under consideration. One method is to immobilise the separated plutonium and residue material in titanate ceramics and glass-ceramics, and recent investigation using plutonium and surrogate species has developed confidence in this approach ${ }^{9-14}$. These wasteforms target zirconolite, prototypically $\mathrm{CaZrTi}_{2} \mathrm{O}_{7}$, as the plutonium host phase, which is known to have excellent aqueous durability and radiation tolerance ${ }^{15,16}$. It has been demonstrated that waste packages could be effectively manufactured by hot isostatic pressing, with the advantage of batchwise processing in a

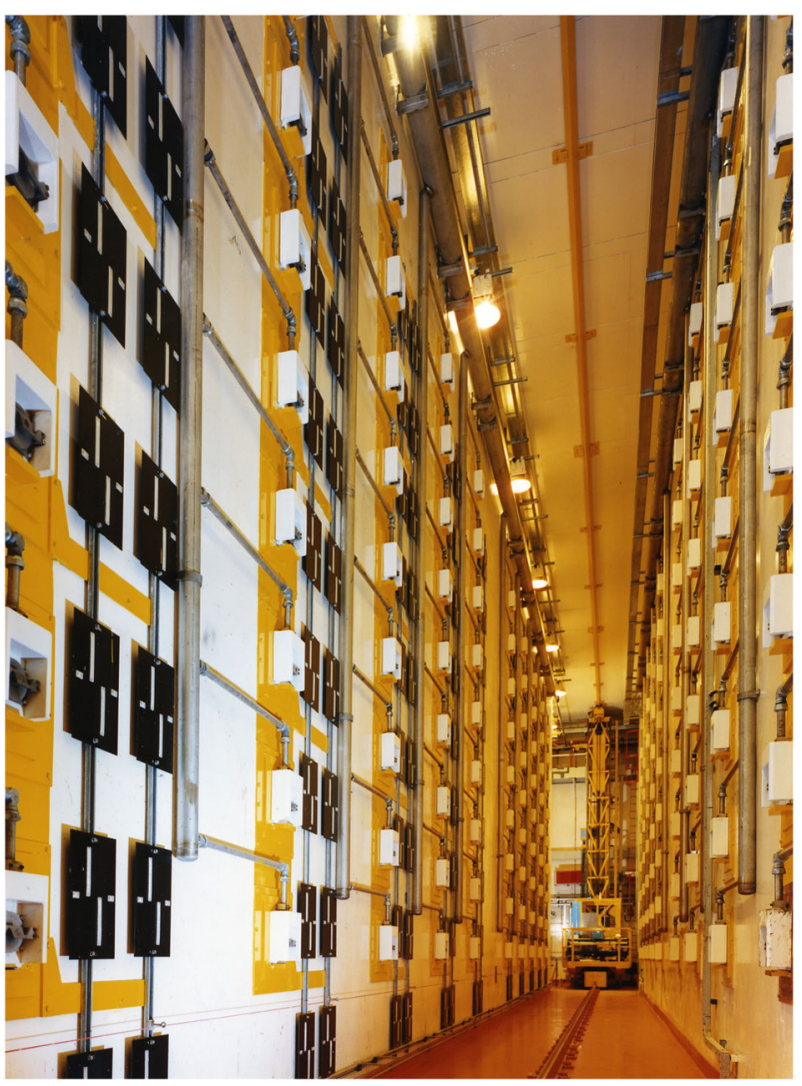

Fig. 1 Sellafield plutonium product store. View of the interior of a Sellafield plutonium product store (reproduced with permission of the copyright holder, the Nuclear Decommissioning Authority).

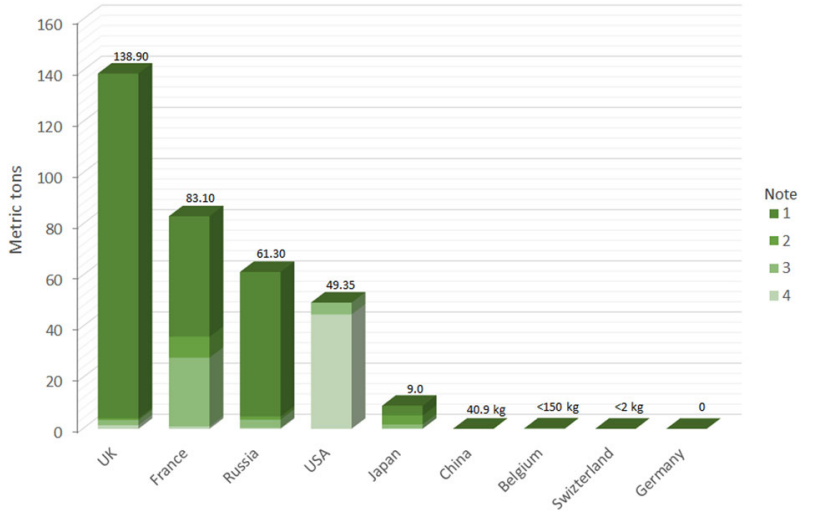

Fig. 2 Worldwide inventories of declared separated plutonium as of 31 December 2018 (except China-2017), as reported to IAEA under INFCIRC/549. Total shown for each reporting member state, comprising: (1) Unirradiated separated plutonium in product stores at reprocessing plants; (2) unirradiated separated plutonium in the course of manufacture or fabrication and plutonium contained in unirradiated semi-fabricated or unfinished products at fuel or other fabricating plants or elsewhere; (3) plutonium contained in unirradiated MOX fuel or other fabricated products at reactor sites or elsewhere; (4) unirradiated separated plutonium held elsewhere.

hermetically sealed container, produced to near net shape specification ${ }^{10-14}$. Recent research has focused on the development of a furnace containment system to enable the hot isostatic pressing of small scale waste packages incorporating UK plutonium, building on laboratory demonstration studies ${ }^{17}$. Alternatively, a variant of the MOX fuel fabrication process could 
be utilised to immobilise plutonium in such a ceramic material or in "disposal MOX", sometimes referred to as "low specification MOX", which would be disposed without irradiation ${ }^{18}$.

Whilst there is confidence in the technical feasibility of immobilisation approaches, considerable research and development remains to be undertaken, before such technology could be deployed, which would be "first of a kind" at industrial scale. For example, the wasteform formulation must be adequately underpinned by extensive surrogate and plutonium active studies, at laboratory and demonstration scale, to understand the phase diagram, define the operational envelope and recovery from maloperations. The post-closure safety assessment for the disposal of such wasteforms is complex, due to the coupled nature of the degradation processes, which will progress over $10^{5}$ years ${ }^{15,16}$. For example, self-radiation damage will induce a crystalline to amorphous phase transition during the period of container integrity. This may result in micro-cracking of the wasteform, increasing the surface area available for dissolution reactions, which could plausibly result in differential release of fissile material and neutron poisons incorporated within the wasteform as a safeguard against criticality. Understanding of the impact of these coupled degradation processes on the long term wasteform evolution and alteration, remains fragmented, but is clearly of crucial importance for post closure safety and criticality assessments. In this context, a review and further investigation of relevant natural analogue systems will provide useful long term insight into wasteform degradation mechanisms, at realistic rates, in addition to accelerated laboratory studies. To ensure that the necessary holistic understanding and the evidence base is developed, a roadmap has been developed to plan and guide the UK research programme.

\section{INTERIM SURFACE STORAGE}

Both plutonium reuse or immobilisation options are subject to commercial and technical uncertainty and would require at least 15 years to implement, and a further $30-50$ years of mission operation. The separated plutonium will, therefore, require several decades of continued storage, irrespective of the final decision to reuse or immobilise. The Nuclear Decommissioning Authority is investing in the design, construction and operation of new fit for purpose stores and plutonium treatment and repackaging facilities, with a lifetime extending to 2120 , at a cost of $£ 3.5$ billion ${ }^{1}$.

It is known that package degradation during storage depends on complex internal radiation chemistry, understanding of which is, therefore, essential to underpin prolonged storage. In the case of $\mathrm{PuO}_{2}$ arising from Magnox reprocessing, the package comprises a welded outer steel container, and a polyethylene bagged inner screw-top aluminium container. Initially, these cans undergo depressurisation, as a result of complex thermal and radiolytic oxidation reactions of the polyethylene bag, involving nitrogen oxides formed by radiolysis of $\mathrm{N}_{2}$ and $\mathrm{O}_{2}{ }^{19}$. $\mathrm{PuO}_{2}$ produced from ThORP (the Thermal Oxide Reprocessing Plant) was packaged under $\mathrm{Ar}$, in a stainless steel fabricated triple package comprising a screw top inner, vented intermediate, and welded outer container. These packages potentially develop higher internal pressure due to the greater thermal output of ThORP plutonium and outgas of He produced by alpha decay ${ }^{19}$. There remains ongoing debate over the role of $\mathrm{PuO}_{2}$ reaction with adventitious water within sealed storage containers, producing $\mathrm{PuO}_{2+x}$ and $\mathrm{H}_{2}{ }^{20}$. In the UK context it has been shown that if there is such a direct reaction between $\mathrm{PuO}_{2}$ and adsorbed water, then surface recombination mechanisms must consume $\mathrm{H}_{2}$, inhibiting package pressurisation at storage relevant humidity ${ }^{19}$. At a microscopic level, He accumulation is reported to lead to embrittlement and disintegration of $\mathrm{PuO}_{2}$ ceramics, after several decades of storage, which may be an important consideration for MOX fuel fabrication and immobilisation options ${ }^{21}$. A small quantity of UK plutonium was packaged in polyvinyl chloride (PVC) bags, thermal and radiolytic degradation of which produced $\mathrm{HCl}$, leading to chloride contamination of the contained $\mathrm{PuO}_{2}{ }^{22,23}$. Recent research has shown that such material may be stabilised for future storage by thermal treatment to remove chloride contamination, followed by repackaging under dry $\operatorname{argon}^{22}$. A zirconolite glass-ceramic wasteform has been developed for the immobilisation of contaminated plutonium and residues, for which chlorine solubility in the glass phase has been demonstrated to exceed the conservatively estimated inventory at the envisaged incorporation rate $^{24}$. An upstream heat treatment facility to remove chloride contamination, as specified in the current conceptual flowsheet, would therefore not be required from the perspective of wasteform compatibility, which could de-risk the waste treatment technology roadmap.

\section{THE WAY FORWARD}

It may be appreciated that whilst the UK government has a clear plutonium management policy, a final decision on the implementation of reuse or immobilisation is not immediately required. Both an immobilised product and used MOX fuel will require a geological disposal facility as an end point, for which the siting process may require a decade or more. As highlighted here, a considerable programme of research, in partnership with universities and commercial organisations, is underway to inform strategy and a decision on implementation. Whether or not the UK plutonium inventory is reused as MOX fuel, a proportion of the material is known to be in an unsuitable condition for fuel fabrication and will likely require immobilisation and disposal, along with plutonium residues ${ }^{1,2}$. The immobilisation matrix and manufacturing process required to treat these materials would also be applicable to inventory immobilisation, albeit at a larger scale to achieve the necessary throughput. For the foreseeable future, developing the technical maturity of these approaches and understanding the evolution of plutonium during storage are clearly of high importance, to ensure effective waste management, to underpin potential inventory immobilisation, and to assure safe storage. At the same time, it is evident that the UK has committed to a strategy for plutonium management which will continue for many decades. A further priority issue, therefore, is maintaining the knowledge, skills and capability to work with plutonium and highly active alpha materials to support the plutonium management mission ${ }^{10,22,23,25}$. Recognising this challenge, the Nuclear Decommissioning Authority Alpha Resilience Capability programme will seek to ensure this critical expertise is maintained.

The challenge posed by the UK plutonium inventory is complex, neither reuse nor immobilisation are immediately deliverable options, but considerable research has been undertaken, and will continue, to support a final decision on the disposition of this material. As highlighted here, understanding the degradation of plutonium during storage, its impact on MOX fuel and wasteform manufacture, and the degradation of these products in the disposal environment, are of critical importance in assuring a safe and secure end point for this enigmatic material.

\section{DATA AVAILABILITY}

There are no primary data to be made available in connection with this analysis. Data relevant to Fig. 2 is available from IAEA: https://www.iaea.org/publications/ documents/infcircs/communication-received-certain-member-states-concerningtheir-policies-regarding-management-plutonium.

Received: 12 May 2020; Accepted: 7 August 2020; Published online: 11 September 2020 


\section{REFERENCES}

1. Nuclear Decommissioning Authority, 2019. Progress on Plutonium Consolidation, Storage and Disposition, https://assets.publishing.service.gov.uk/government/ uploads/system/uploads/attachment_data/file/791046/Progress_on_Plutonium. pdf (2019).

2. Hyatt, N. C. Plutonium management policy in the United Kingdom: the need for a dual track strategy. Energy Policy 101, 303-309 (2017).

3. Department of Energy and Climate Change, 2011. Management of the UK's plutonium stocks: a consultation on the long-term management of UK owned separated civil plutonium, https://www.gov.uk/government/uploads/system/ uploads/attachment_data/file/42766/1243-uk-plutonium-stocks.pdf (2011).

4. Department of Energy and Climate Change, 2013. Management of the UK's plutonium stocks: consultation response, https://assets.publishing.service.gov.uk/ government/uploads/system/uploads/attachment_data/file/42773/3694-govtresp-mgmt-of-uk-plutonium-stocks.pdf (2013).

5. Nuclear Decommissioning Authority, 2010. Plutonium-Credible Options Analysis (Gate A), Sms/TS/B1-PLUT/002/A, https://www.nda.gov.uk/publication/ plutonium-credible-options-analysis-redacted-2010 (2010).

6. Morrison, S. L. \& Parks, G. T. The effect of Am241 on UK plutonium recycle options in thorium-plutonium fuelled LWRs_-Part I: PWRs. Ann. Nucl. Energy 135, 106952 (2020).

7. Morrison, S. L. \& Parks, G. T. The effect of Am241 on UK plutonium recycle options in thorium-plutonium fuelled LWRs_-Part II: BWRs. Ann. Nucl. Energy 135, 106974 (2020).

8. Organisation for Economic Co-operation and Development, 2018. Uranium 2018: Resources, Production and Demand, NEA 7413, http://www.oecd-nea.org/ndd/ pubs/2018/7413-uranium-2018.pdf (2018).

9. Blackburn, L. R. et al. A systematic investigation of the phase assemblage and microstructure of the zirconolite $\mathrm{CaZr}_{1-\mathrm{x}} \mathrm{Ce}_{\mathrm{x}} \mathrm{Ti}_{2} \mathrm{O}_{7}$ system. J. Nucl. Mater. 535, 152137 (2020).

10. Thornber, S. M. et al. A preliminary validation study of $\mathrm{PuO}_{2}$ incorporation into zirconolite glass-ceramics. MRS Adv. 3, 1065-1071 (2019).

11. Thornber, S. M., Heath, P. G., Da Costa, G. P., Stennett, M. C. \& Hyatt, N. C. The effect of pre-treatment parameters on the quality of glass-ceramic wasteforms for plutonium immobilisation, consolidated by hot isostatic pressing. J. Nucl. Mater. 485, 253-261 (2017).

12. Squire, J., Maddrell, E. R., Hyatt, N. C. \& Stennett, M. C. Influence of lubricants and attrition milling parameters on the quality of zirconolite ceramics, consolidated by hot isostatic pressing, for immobilization of plutonium. Int. J. Appl. Ceram. Technol. 12, 92-104 (2015).

13. Maddrell, E. R., Thornber, S. \& Hyatt, N. C. The influence of glass composition on crystalline phase stability in glass-ceramic wasteforms. J. Nucl. Mater. 456, 461-266 (2015).

14. Maddrell, E. Hot isostatically pressed wasteforms for future nuclear fuel cycles. Chem. Eng. Res. Des. 91, 735-741 (2013).

15. Ewing, R. C. Plutonium and "minor" actinides: safe sequestration. Earth Planet. Sc. Lett. 229, 165-181 (2005).

16. Ewing, R. C. Ceramic matrices for plutonium disposition. Prog. Nucl. Energ. 49, 635-643 (2007).

17. Gardner, L. J., Walling, S. A. \& Hyatt, N. C. Hot isostatic pressing: thermal treatment trials of inactive and radioactive simulant UK intermediate level waste. IOP Conf. Ser.: Mater. Sci. Eng. 818, 012009 (2020).

18. Macfarlane, A. M. Another option for separated plutonium management: Storage MOX. Prog. Nucl. Energ. 49, 644-650 (2007).

19. Sims, H. E., Webb, K. J., Brown, J., Morris, D. \& Taylor, R. J. Hydrogen yields from water on the surface of plutonium dioxide. J. Nucl. Mater. 437, 359-364 (2013).

20. Haschke, J. M., Allen, T. H. \& Morales, L. A. Reaction of plutonium dioxide with water: formation and properties of $\mathrm{PuO}_{2+\mathrm{x}}$. Science 287, 385-387 (2000).
21. Ronchi, C. \& Hiernault, J. P. Helium diffusion in uranium and plutonium oxides. J. Nucl. Mater. 325, 1-12 (2004).

22. Sutherland-Harper, S. et al. Characterisation and heat treatment of chloridecontaminated and humidified $\mathrm{PuO}_{2}$ samples. J. Nucl. Mater. 509, 654-666 (2018).

23. Webb, K. et al. Thermal Processing of Chloride-Contaminated Plutonium Dioxide. ACS Omega 4, 12524-12536 (2019).

24. Thornber, S. M. Solubility, speciation and local environment of chlorine in zirconolite glass-ceramics for the immobilisation of plutonium residues. RSC Adv. 10, 32497-32510 (2020).

25. Nuclear Decommissioning Authority, 2019. Pressure treatment for plutonium stockpile, https://www.gov.uk/government/case-studies/pressure-treatment-forplutonium-stockpile (2019).

\section{ACKNOWLEDGEMENTS}

The author is grateful to the Nuclear Decommissioning Authority, Royal Academy of Engineering, and Engineering \& Physical Sciences Research Council for funding support (under grant references: EP/S01019X/1, EP/R511754/1, EP/T011424/1). The author is grateful to the three anonymous reviewers, and colleagues, for their helpful critique to improve this article.

\section{AUTHOR CONTRIBUTIONS}

The author is solely responsible for the conception of the analysis presented; the author drafted and revised the paper; approved the final version is accountable for the accuracy and integrity of the analysis and its interpretation.

\section{COMPETING INTERESTS}

The author declares no competing interests.

\section{ADDITIONAL INFORMATION}

Correspondence and requests for materials should be addressed to N.C.H.

Reprints and permission information is available at http://www.nature.com/ reprints

Publisher's note Springer Nature remains neutral with regard to jurisdictional claims in published maps and institutional affiliations.

(i) Open Access This article is licensed under a Creative Commons c. Attribution 4.0 International License, which permits use, sharing, adaptation, distribution and reproduction in any medium or format, as long as you give appropriate credit to the original author(s) and the source, provide a link to the Creative Commons license, and indicate if changes were made. The images or other third party material in this article are included in the article's Creative Commons license, unless indicated otherwise in a credit line to the material. If material is not included in the article's Creative Commons license and your intended use is not permitted by statutory regulation or exceeds the permitted use, you will need to obtain permission directly from the copyright holder. To view a copy of this license, visit http://creativecommons. org/licenses/by/4.0/.

(c) The Author(s) 2020 